The Dhaka University Journal of Linguistics: Vol. 2 No.3 February, 2009 Page: 91-100, Published on December 2009 by the Registrar, Dhaka University ISSN-2075-3098

\section{Orchestrating Cultural Differences in Pedagogy: A Transformational Experience}

\author{
Zakir Hossain Majumder ${ }^{1}$
}

\author{
1. Assistant Professor, Department of English \& Humanities, \\ University of Liberal Arts Bangladesh
}

\section{Abstract:}

In this world of plurality and polivocality, it has become a challenge for both educators and learners to negotiate their voices and opinions on a number of things the way that they should move forward and hence give the pedagogy a go, keeping the tunnel open for any sort of heightened understanding between parties concerned. I, like others, in the same boat, feel the exigency of this orchestration, as I encounter the problems of differences in opinions between my students and me both inside and outside the classroom. Negotiating these differences between students and their teachers and also among themselves bring forth a practical challenge for both parties. The study in progress has actually grown out of my personal observations and interactions with my students inside and outside the classrooms. It also zooms in on my continual effort to find the middle ground to deal with these practical concerns. It also takes how my interactions with students have transformed the way I have been teaching for a long time. By the way, it would be apposite to mention that my purpose is here just to exploit the parameter of contact zone to show how it heleds me to resolve the crisis I experienced while teaching and interacting with my students. It does in no way encompass the whole process of learning and teaching in its entirety in view of the concepts of them having emerged in keeping with recent developments in the field.

Key words: Culture, Transformation, Contact zone.

\section{Introduction}

Culture has become a vehemently significant issue in connection with teaching English in a country where English is The Dhaka University Journal of Linguistics not the mother tongue. Voices are as many as the students in the class in terms of differences in their likes and dislikes, and opinions about a number of things being culturally bound and oriented. Negotiating these differences between students and their teachers and also among themselves put forth a practical challenge both for teachers and students. The current study that follows has actually grown out of my personal observations and interactions with my students inside and outside the classrooms and also out of my continual effort to find the middle ground to deal with these practical concerns. It also takes how my interactions with students have influenced the way I have been teaching for a long time.

My personal experiences as an educator contribute largely to bringing about a change in my philosophy of teaching in which the most meaningful learning takes place when students are motivated and interested. It is my belief that the way to achieve this is by giving students a voice in the learning process, and by assisting them in finding connections in the curriculum with their own life and interests. Thus, "pedagogists", as Laurie Grobman (1999) maintains, "... have turned to the resistance model, which proposes that we encourage students' appropriation of academic discourse to enable them to critique it" (432). By allowing students to bring their own stories, experiences, ideas, and critiques into the classroom, this provides the students with opportunities to work together, to learn from one another, and respect one another's differences-social and cultural.

\section{Previous experiences of teaching}

My previous method of teaching was teacher-centered one in which, as is culturally believed and hence has been practiced in our part of the world, the teacher is a giver while the student a receiver, setting aside the voices of the students. Nevertheless, it worked out very badly as it gave rise to a sort of inertia and dissatisfaction among the students failing to voice their minds. And my changed philosophy of education, thus, concentrates

Vol. 2 No.3 February, 2009 
on student-centered one. I believe in focusing on individual needs, and involving students in the process of their learning. I am very uncomfortable with the teacher-centered philosophy of perpetualism, in which multiculturalism and gender issues are evaded in the curriculum. Hence I see my philosophy of teaching reflected in and supported by the theoretical model of Mary Louis Pratt's “contact zone".

\section{A Theoretical Approach to my Transformation}

The "contact zone" has emerged as an important concept for understanding cultural differences in educational institutions. According to Mary Louise Pratt, "contact zone" is "social spaces where cultures meet, clash, and grapple with each other, often in contexts of highly asymmetrical relations of power" (1992:4). Pratt argues that education is negotiated in contact zones where students of diverse backgrounds learn to communicate with one other and with their teachers. Remaining focused on mere academic content, educators lose sight of the issue of cultural difference, thus misreading or ignoring important dynamics in their classrooms. Pratt argues that students themselves devise different strategies to deal with the contact zone. The effectiveness of the strategies they choose has much to do with their ultimate success in classes and in the larger cultural space of the institution. Students must deal with their own unique backgrounds, especially their language practices, in classrooms that demand standard academic practices. Pratt describes the creative approaches students may develop to negotiate this conflict as the "arts of the contact zone." My purpose is cash in on usefulness of the contact zone as a guiding pedagogical principle for teachers and students. I believe that by using the contact-zone theory, educators can develop a more reflective and productive educational practice.

\section{The context of the activity}

The students I teach here at University of Liberal Arts Bangladesh are of between 18-21 years, who are mostly from well-off middle class families (in Bangladesh practice) background. They are of mixed maturity and experience The Dhaka University Journal of Linguistics bearing the characteristics of their age and culture in which they have grown up. My class has students ranging from 10 to 15 in number, who previously had courses on literature, General education, and some courses on humanities in keeping with the vision of liberal education, the reward of which lies in itself. Liberal education puts weight on the free exercise and association of knowledge facilitating 'polyvocality' consisting of various discourses (Holquist, [1990] 2002: 34, 108). Nevertheless, the problems I have been faced with are significant in relation to differences - cultural or others.

\section{The intended learning outcomes of the new teaching}

\subsection{A Study in Practice}

During Spring Semester 2009, I taught the course "English 303: Short Stories" designed to introduce students to the short fiction of pre-modern and modern periods through short stories of England, Europe and Americas.

\subsection{The aims of the course are}

- To introduce you to a range of major authors and works of the period

- To introduce you to key themes, issues and problems

- To develop a broad historical understanding of Victorian prose production at this time

- To develop literary critical skills of contextualization, close analysis, and argumentation

- To further develop your research skills and to prepare you for the research paper

$5.3 \mathrm{By}$ the end of the module, students should be able to demonstrate

- An ability to relate literary texts to relevant historical, social and cultural contexts 
- An ability to identify central themes in the literature of the period

- An ability to evaluate and analyze the course texts

- An ability to read key passages from the set texts critically and in detail

- An ability to select, comment on and apply relevant research materials

A lesson plan for each subsequent class automatically grew out of the discussion and negotiation between my students and me and hence was set in concert with the students.

The practical problem we faced in terms of choosing short stories by writers of Europe, England and America is enormous. I, as a faculty-instructor, came up with my own inventory of about 15 short stories by the writers of said regions - the list is not a symmetrical one, though, with England having more in number than the other two regions. While I wanted to stick to my own list, some of my students were in favour of including short stories from other regions such as South Asia, Africa, Latin America and Caribbean Islands, being prone to embrace the works from periphery. The logic behind their stance is not untenable inasmuch as the latest theoretical tendency is to break the hierarchy between center and periphery. Finding them basing on solid ground of logic, I negotiated and hence included some stories from the regions in questions, ramifications of which was very fruitful. Another confrontation I faced with my students was the selection of topics for term final papers. Once again, as is the case with short story selection, I came up with my own selection of topics that they found exclusionary. In my effort to find a middle ground, I called for at least three topics from each student and asked them to hand in these in the next class. Accordingly, they did it, and following a discussion and a mutual review, we were able to select some topics for our term papers, thus resolving the tension between my students and me.

Another problem I faced with my students is that of pronunciation in terms of accent and intonation determined by so called Standard English. One day I got them read excerpts from a short story while explaining them following their turns. I found the smell of dialect in their accents bearing the traces of regional accents they have been used to for a long time.

The intonation pattern, as is believed, carries meaning in time and place. And Bengali being a tonal language possesses different patterns from those of English. Bengali students should recognize these tonal patterns in English provided that they have to speak Standard English. Moreover, they have had the impact of their local tenor of speech on their pronunciation of English. It is nearly impossible on the part of an educator like me to bring about any change over the night in their accents of English since old habits pass away hard. Consequently, I had to negotiate by way of converging different accents tinged with different vernacular tenors and tones. Thus, the end result is a contact zone welcoming a particular taxonomy of English — a Bangladeshi English with different local accents, indeed.

\section{How does it work in practice?}

A literature classroom, I believe, can be ideal for accommodating students of varying ability and with diverse cultural and economic backgrounds. Peer interactions and active learning can be made an integral part of the classroom to enrich individual learning. To this end, they are encouraged to draw largely on authors culturally as diverse as Jane Austene, Charles Dickens, Saul Bellow, Gustave Flaubert and the like, and short stories by different fabulous writes from Europe, North and South Americas, and other parts of the world. Also, with the wide range of involvement capable of being covered 
through a study in literature, at least students may be reached by channeling their unique interests in the classroom. By the same token, their activities are assessed both formally and informally through discussions, presentations, quizzes, sitdown tests and the like.

\section{Pros and Cons}

Literary study is a broad field that can be linked to an assorted range of subjects including psychology, sociology, anthropology, ethnography, science, and history-an interdisciplinary approach corresponding to a 'zone of contact' in literature, indeed. Literature can be the vehicle through which the students learn about ideas prevalent through different historical and cultural contexts. For instance, teaching either Saul Bellow's Seize the Day or The Death of a Sales Man by Arthur Miller can give students a better understanding of how individuals have responded to their current society and culture and its relationship to the past. The human effect can be felt through identifying oneself with characters created with emotional relevance, thereby adding weight to an outlined dates-and-facts study of history. In this fashion, it is planed to urge students to think beyond their individual horizons to process thoughts through a multicultural or transcultural perspective - a perspective in which, according Mary Louise Pratt, "subordianted or marginal groups select and invent from materials transmitted to them by a dominant ... culture" (6).

Most of the students come up with their opinions in support of the way I intend to carry out the said learning process. A few, however, cherish different opinions I try to negotiate or accommodate into the process as part of contact zone to let them voice their minds freely. They also have their say about the performence of the teachers and can evaluate them independently, which the teachers in turn can take into account to bring about necessary changes in their activities thus improving the quality of their teaching.

The Dhaka University Journal of Linguistics

\section{Further developing the methodology}

Other than the approach mentioned above, thare is a good number of aproaches students can draw on in line with the demand of cotact zone facilitating other voices or approaches. To make our learning engaging, agile, motivating, and interesting, we can shift from one approach to anotherformal, informal, and idiosyncratic - to serve our own purpose and derive best from materials available. In this world of chaos and confusion - real, fashioned or textualized-we need to draw on many paradigms to grasp the continually shifting moments in time and place.

\section{Resources for students}

Resources are of many but uses are smomewhat limited and restrictive as per our need and puspose. Nevertheless, I rely on different resources and at times prepare handouts on relevant topics to help the students to cope with their courses in many ways. The websites I draw on are JSTOR (www.jstor.org), Boston Review (http://bostonreview.net), www.english.uiuc.edu, and advise the students to do the same to cash in on them. I also ask my students to read Time Literary Suppliment, The New Yorker, and The Pelican Guide to English Literature (ed. Boris Ford). And if I ever refer to any source, I must name the JSTOR - a valuable pool of scholarly journals contributed to by resourceful persons.

\section{Hot tips}

I hope to learn from students as well as teach the principles of learning and teaching that I feel will benefit them. My sense of learning is that it is a life-long process, and adults as well as children and teenagers are constantly expanding their perspective on the world. By engaging myself with students I will better my understanding of the unique needs, emotions, and beliefs students may have. Apart from being didactic, I wish other people would think in the same line. As I strongly 
believe in the idea of contact zone, I would not like to impose anything on anyone; rather, it sounds the best way to me that I had better place the way I feel like while experiencing all this. Educators are free either to accept or reject-in fact, they have to learn how to transform themselves by way of their own interactions with students.

\section{Conclusion}

If culture and language are inextricable part of each other, then we need to make an endeavor to learn and teach cultures systematically and the way we learn other aspects of language. Nevertheless, problems arise in deciding what culture to approach in terms of teaching and learning, perhaps, by way of inducing cultural stereotypes and thus ignoring individual learners in the process of doing culture. There is no denying that it is impossible to stand everything on equal feet; nevertheless, we can carry on our negotiation persistently to dwindle the unequal or 'asymmetrical relationship' between peoples of diverse cultures and opinions the world over. We should also encourage the students or learners to mull over comparisons between cultures and help them come up with their own perceptions about the cultures they are reading, which will, in turn, help them have the better understanding of theirs. We negotiate to connect, indeed.

\section{References}

Elmborg, James. 2006. Libraries in the Contact Zone: On the Creation of Educational Space. Reference \& User Services Quarterly, 46:1: 65-64.

Grobman, Laurie. 1999. Beyond Internationalization: Multicultural Education in the Professional Writing Contact Zone. Journal of Business and Technical Communication, 13: 427-448.

Holquist, Michael. 1990. Dialogism: Bakhtin and his World. London and New York: Routledge.

The Dhaka University Journal of Linguistics
Majumder, Zakir H. 2006 Beyond Blurred Genres: Literature, Anthropology and Ethnography. Spectrum (Journal of the Department of English, University of Dhaka), 4: 61-79.

Pratt, Mary Louise. 1992. Imperial Eyes: Travel Writing and Transculturation. London: Routledge.

Email contact: zakirmajumder@yahoo.com 